\title{
A Construção Sociológica da Raça no Brasil ${ }^{1}$
}

Sérgio Costa

\section{Resumo}

Partindo da constatação de que as adscrições raciais no Brasil implicam desigualdades sociais que podem ser reunidas de sorte a definir dois grupos populacionais polares, brancos e não brancos, al guns estudos raciais adotam o conceito (não biológico) de raça como categoria sociológica e política ampla. Válida e mesmo imprescindível no âmbito do estudo das desigualdades raciais, a categoria raça, quando tran sformada em instrumento geral deanálisee desiderato normativo, leva a uma compreensão incompleta da formação nacional brasileira, a uma visão obje tivista das relações sociais e à redução das identidades sociais a sua dimensão político-instrumental.

Palavras-chave: desigualdades raciais, identidade cultural, reconhecimento social no Brasil 
Sérgio Costa

\section{Abstract}

The Sociological Construction of Race in Brazil

Establishing positively that race records in Brazil lead up to social inequalities that might permit a definition of two basic population groups- whites and non-whites-, someracial studies adopt the concept (non-biological) of race as a general sociological and political category. The race category, al though essential for the studies of race inequalities, when transformed in a general instrument of analysis and normative desideratum, leads to an incomplete comprehension of the Brazilian national formation, to an objectivist vision of the race relations and to a reduction of the social identities to its political-instrumental dimension.

Keywords: race inequalities, cultural identity, social acknowledgement in Brazil, race categories.

\section{Résumé}

\section{La Construction Sociologique du Concept de Race au Brésil}

Après avoir constaté que les façons dont la notion de race a été construite au Brésil impliquent des inégalités sociales qui peuvent être assemblées de sorteà définir deux grands groupes de populations, Blancs et non-Blancs, quelques études sur les races ont adopté le concept (non pas sous l'aspect biologique) de race comme large catégorie sociale et politique. Bien qu'utile, voire incontournable, en ce qui concerne l'étude des inégalités raciales, la catégorie race - lorqu'elle est prise en tant qu'instrument général d'analyse vouéà dicter des normes - mèneà une compréhension incomplète de la formation nationale brésilienne, à une vision objectiviste des rapports sociaux ainsi qu'à une réduction des identités sociales à leur dimension politique et instrumentale.

M ots-clé: inégal ités raciales, identité culturelle, reconnaissance sociale au Brésil 
0 primeiro ato moral consiste em não sobrepor a dupla do bem e do mal à dupla do 'eu' edo 'outro'.

(T zevan Todorov).

T anto pelos bons quanto pelos maus motivos a formação nacional brasileira desde muito interessou pesquisadores e ideólogos para além dasfrontei rasnacionais. A mitologia da brasilidade mestiça, integradora de to das as etnias e ponto de equilíbrio das diferenças culturais, canonizada por G ilberto Freyre em Casa Grande \& Senzala, constituiu, em muitos momentos da história recente, a imagem contrastiva, ora latente, ora intrigante, dos discursos identitários em nações que, sob todos os demais aspectos, pareciam, a seus próprios membros, muito melhores que o Brasil. Assim, no âmbito do "Projeto U nesco", conforme se lê na reconstrução esclarecedora de M aio (2000), as N ações U nidas buscavam estudar e apresentar ao mundo aquilo que se considerava uma experiência "singular e bem-sucedida" de acomodação de diferenças raciaise étnicas. Anos antes, por razões opostas, o modelo brasileiro havia interessado aos pesquisadores raciais do Terceiro Reich (K rieger, 1940). Trata-se, nesse âmbito, da condenação enfática e veemente do festejamento político da "mistura racial" e da ênfase na necessidade de preservação da "integridade genética" dos brancos de ascendência ariana, aos quais caberia liderar o processo de condução do Brasil ao desenvolvimento.

Tratado, portanto, numa perspectiva histórica, a crítica conjunta do sociólogo francês Pierre Bourdieu, recentemente fal ecido, e do antropólogo Loïc W acquant (Bourdieu \& W acquant, 1998) à nova geração de pesquisadores estadunidenses e brasileiros dedicados ao estudo das "relações raciais" no Brasil não chega propriamente a constituir uma novidade. 0 que há de novo na polêmica équeo caso brasileiro étomado pelosdoisintelectuaisfranceses com o objetivo de demonstração empírica da tese mais ampla que procuram desenvolver, a saber, a constatação da existência de 
um imperialismo cultural e acadêmico dos americanos no mundo contemporâneo.

A interven ção etnocêntrica estadunidense ganharia, segundo Bourdieu eW acquant, particular nitidez nos estudos sobre as desigualdades "etno-raciais" observadas no Brasil. Aqui, através do patrocínio de instituições filantrópicas como a Fundação Ford e a Fundação R ockefeller, bem como por meio do treinamento de cientistas brasileiros e da produção intelectual de pesquisadores norte-americanos, muitos deles afro-descendentes, o imperialismo americano se manifestaria na construção do campo de estudos das relações raciais, guiado pelo imperativo de que se interprete as relações sociais no Brasil a partir da dicotomia bipolar branco-negro própria da sociedade americana. U ma tal transposição imprópria e obtusa de model os analíticos seria operada exemplarmente por M ichael H anchard (1994), o qual estudaria a história do movimento negro brasileiro como se tratasse do "Civil Rights M ovement", ignorando que

[...] no Brasil, a identidade racial é definida por referência a um continuum de "cor", isto é, através do uso deum princípio flexível ou difuso que, levando em conta traçosfísicos, como a cor da pele, a textura do cabelo e a forma dos lábios e do nariz e a posição de classe (os rendimentos e a educação notadamente) engendra um grande número de categorias intermediárias. (Bourdieu \& W acquant, 1998:112)

Os artigos reunidos no número especial da revista Theory, Culture and Society (vol. 17, no 1, 2000) parecem mostrar, de forma convincente, que o conceito de "imperialismo", em qualquer das conotações que mereceu historicamente, não traduz de forma adequada as relações entre cientistas sociais e movimentos sociais do N orte e do Sul, no mundo atual. Ainda que não sejam simétricas, tais relações encerram vicissitudes que extrapolam o tipo de dominação unilateral expressa pelo conceito de imperialismo, em suas diferentes extrações. Todas as sociedades contemporâneas contêm, em alguma medida, um componente pós-nacional, de sorte que tanto as agendas de pesquisa quanto os atores sociais se constituem no campo de tensões entre determinantes internos e externos às fronteiras nacionais (sobre a "constelação pós-nacional", ver Costa, 2001b). Somente quanto se toma em consideração o complexo jogo de interpenetrações sociais e alianças transnacionais é que se pode entender, por exemplo, por que temas como o meio ambiente, a igualdade de gênero ou a luta contra a discriminação racial ganham, nas agendas política e acadêmi- 
ca brasileiras, uma importância desproporcional ao peso político dosatores sociaisqueas representam no contexto nacional. $\mathrm{H}$ á, seguramente, nesses casos, uma conexão entre as agendas dos movimentos sociais na França, Alemanha ou Estados U nidos e países como o Brasil quenão pode, éóbvio, ser condenada politicamente como expressão imperialista.

A inadequação conceitual parece constituir, contudo, a dimensão menos relevante da crítica de Bourdieu eW acquant ao imperialismo americano, a qual pareceorientada, no âmbito da Realpolitik acadêmica, muito mais pela "responsabilidade" que pelo "convencimento". N ecessita, por isso, ser interpretada a partir da lógica e dos nexos internos do "campo" acadêmico, tarefa que só pode ser real izada adequadamente por cientistas que conhecem as vicissitudes dos ambientes institucionais em tela, como bem demonstra a análise de W ieviorka (2000). Limita-se, por isso, aqui aos aspectos teórico-metodológicos da crítica, buscando fazer do debate presenteo moteparauma discussão, exploratória esujeitaa revisões, dos usos da categoria raça no âmbito dos estudos raciais relacionados com o Brasil.

D einício, háquese constatar quenão hámonolitismo teórico, político ou quanto à qual idade dos trabal hos recentes produzidos no campo de pesquisa aqui denominado de estudos raciais. Trata-se, na verdade, de um conjunto variado de contribuições que ganham novo impulso ao final dos anos 70 através dos trabaIhos de $\mathrm{C}$ arlos $\mathrm{H}$ asenbalg e $\mathrm{N}$ elson do V. Silva (cf. $\mathrm{H}$ asenbalg, 1979; $H$ asenbalg \& Silva, 1988; Silva \& $H$ asenbal g, 1992; $H$ asenbalg, 1995, Silva \& H asenbalg, 1999; Silva, 2000) equetêm como ponto de partida comum a compreen são de que o viés "racial" das desigualdades sociais no Brasil não constitui uma mera reprodução de desvantagens históricas; o desfavorecimento dos grupos não-brancos continua embutido nas relações sociais. Como ponto de partida da análise desenvolvida no presente artigo, sugere-se distinguir, entre os estudos raciais, aqueles trabal hos que dirigem seu foco para o diagnóstico das desigualdades raciais daqueles que procuram fazer da idéia de raça uma categoria geral de análise da sociedade brasileira, estendendo seu âmbito de interesse a um espectro amplo de temas inter-relacionados, tais como o racismo e anti-racismo (Guimarães, 1999), a formação nacional brasileira (G uimarães, 2000, 2000a), o movimento negro ( $\mathrm{H}$ anchard, 1994), a identidadeafro-descen dente(Ferreira, 2000), além de estudos de casos (T wine, 1998) eabordagenscomparativas (W inant, 1994). 
D eve-se ressalvar, contudo, que a linha que separa os dois conjuntos de trabal hos referidos nem sempreénítida. 0 maisadequado, por isso, seria dizer que as considerações críticas que se seguem dirigem-se, primordialmente, a esse segundo momento teórico dos estudos raciais, quando a categoria raça passa a ser utilizada como instrumento analítico geral, referindo-se abaixo a certos problemas legados por tal procedimento. Trata-se, inicialmente, da compreensão incompleta de al guns desenvolvimentos recentes relacionados ao processo de formação nacional, mostrando-se aqui como a centralidade da categoria raça ofusca dimensões fundamentais de um fenômeno multifacetado. Em seguida, procura-se evidenciar que o uso da categoria raça leva a que se estabel eça uma relação de subordinação da cultura à política e que se construa uma escala evolutiva entre as diferentes formas culturais de vida existentes, projetando-se, a partir daí, modelos identitários que passam ao largo das aspirações de reconhecimento ${ }^{2}$ das populações desfavorecidas pelas desigual dades raciais.

$\mathrm{N}$ acionalidade e Raça

0 tom e os termos dominantes no debate racial brasileiro nas últimas décadas do século XIX e primeiras décadas do século $X X$ já foram adequadamente reconstruídos e são hoje bem conhecidos (ver, entre outros, Schwarcz, 1993; M unanga, 1999; H ofbauer, 1999). O diagnóstico hegemônico até esse período apontava a inferioridade defundo biológico dosnegrose mestiços, enquanto os prognósticos variavam de uma avaliação pessimista das possibilidades de se construir sobre tal base humana uma nação progressista nos trópicos (N ina R odrigues, 1935) até a expectativa positiva de que a miscigenação levaria ao embranquecimento - no sentido cromático e genético - paulatino da população (O liveira Vianna, 1923).

O s desenvolvimentos que se seguem a essa fase de dominação do racismo biologicista, que toma a carga genética manifesta nas características físi cas como adscrições infen sas à ação política ou individual, são interpretados de forma controversa na literatura. Interessa aqui reconstruir, ainda que brevemente, a visão oferecida por publicações recentes associadas ao campo das relações raciais, valendo-me, sobretudo, dos trabal hos de Guimarães (1999, $2000,2001)$ que, nesse aspecto, parecem expressivos do conjunto de interpretações existentes. 
G uimarães (2001:20), apoiando-se em J. Skurskiee R. N oiriel, percebe os reflexos da G uerra Franco-Prussiana e da disputa entre o modelo de constituição nacional na França e na Alemanha no processo de formação da identidade nacional no Brasil. Segundo 0 autor, a nacionalidade brasileira teria sido influenciada diretamente pelo esforço francês em construir uma comunidade nacional integrada não pelas origens, mas pelo contrato, diferenciando-se, assim, do nacionalismo alemão de corte étnico-racial. C ontudo, para Guimarães a idéia de nação que acaba prevalecendo, historicamente, na França, éambígua, preservando-se a referência implícita a uma "raça histórica" construída a partir "de memórias coletivas, de experiências históricas e do culto aos ancestrais". ${ }^{3}$

0 s trabalhos de Gilberto Freyre nos anos 30 refletiriam tal influência francesa, herdando dela a ambigüidade no tratamento da raça. O u seja, ao contrário de muitos intérpretes de F reyre (ver, p. ex., A raújo, 1994), G uimarães não entende que o autor opera uma inflexão definitiva no discurso racista dominante. Segundo ele, Freyre rompe com o biologicismo, mas não com a idéia de raça. Para G uimarães, Freyre defende uma "concepção eurocêntica de embraquecimento" que:

[...] passou, portanto, a significar a capacidade da nação brasileira (definida como uma extensão da civilização européia em que uma nova raça emergia) deabsorver eintegrar mestiços e pretos. Tal capacidader requer, demodo implícito, a concordância das pessoas de cor em renegar sua ancestralidade africana ou indígena. "Embranquecimento" e "democracia racial" são, pois, conceitos de um novo discurso racial ista. (G uimarães, 1999:53)

Seguindo as pistas de Freyre, a produção subseqüente, segundo Guimarães, mostrou-se pouco atenta ao caráter racial do modelo de nacionalidade cunhado nos anos 30 , identificando a persistência do tratamento desigual como preconceito de cor enão de raça e, mesmo quando mais tarde, na forma como Florestan Fernandes denunciaria o mito da democracia racial, ele acabaria subsumindo o racismo nas diferenças de classe, negando-Ihe um caráter estrutural, genético para as relações sociais.

$\mathrm{N}$ os anosrecentes, os estudos sobre desigualdade racial, bem como os avanços políticos observados no interior do movimento negro, teriam colocado definitivamente em xeque o mito da democracia racial. Assim, sea nacional idadebrasileira foi construída historicamente como identidade mestiça no 
Sérgio Costa

[...] espaço derepresentação demarcado por três pólos raciais- o branco, o negro e o índio -, se distanciando cuidadosamente de cada um deles [...], [atualmente] o branco de classemédia busca sua segunda nacionalidadena Europa, nos Estados U nidos ou no Japão - ou cria uma xenofobia regional racializada; o negro constrói umaÁfrica imaginária para traçar sua ascendência, ou busca os Estados Unidos como meca afro-americana; os índios recriam a sua tribo de origem. (G uimarães, 2000a: 28)

A incursão dos estudos raciais no processo de formação nacional apresenta desaídaum mérito digno denota: elesidentificam o núcleo heterofóbico das concepç̃os de F reyre. C onstituem, assim, um valioso contraponto às tentativas impróprias observadas nos últimos anos de reabilitação do pensamento político do autor como se se tratasse de expressão da tolerância e do apelo pela convivência plural, haven do mesmo referênciasa Freyrecomo idealizador de algo como um pós-colonialismo avant la lettre (como faz mesmo um autor criterioso como Pieterse, 1998). Analiticamente, contudo, a leitura da obra dos anos 30 de Freyre e do processo de constituição nacional desde então, quando fixada nalente da categoria raça, acaba por identificar como construção do mito da democracia racial um fenômeno de dimensões múltiplas e desdobramentos exten sos. $\mathrm{O}$ u seja, se C asa G rande \& Senzala podeser tomada, da mesma forma que a ficção fundacional em outros países, como um manifesto de (re)fundação da nação, o conjunto de transformações políticas coetâneas à obra não pode ser interpretado como processo de construção de uma ideologia racial. Trata-se, na verdade, no final da década 1930, de uma inflexão profunda e definitiva no processo de redefinição da identidade nacional. Constitui-se, nesse momento, as bases de uma ideologia da mestiçagem que, em seus aspectos culturais, orientaria a ação dos governos brasileiros pel o menos até o fim da ditadura militar (cf. C osta, 2001a). Em tal corpo ideológico, a afirmação de uma "brasilidade mestiça" como unidade da diversidade - nos termos sistematizados intelectual mente por F reyre - é mantida como prérequisito da constituição da comunidade política nacional. ${ }^{4} \mathrm{~N}$ ão obstante, em sua transposição para a política, tal ideário ganha novas determinações; a principal delas corresponde à crença na construção de um futuro próspero comum como objetivo universal elugar imaginário no qual todos os membros da nação, separados pelo passado distinto, se encontrariam.

Pareceser essa orientação para o futuro que constitui o principal legado francês à formação nacional brasileira. G iesen, estu- 
dando o lluminismo eo processo deformação do Estado $\mathrm{N}$ acional na França e na Alemanha, pontua diferenças que nos ajudam a compreender a ideologia que refunda a nação brasileira nos anos 30 e 40. No caso francês, ele mostra que o ideal iluminista é cosmopolita na medida em que vê os diferentes povos nos diversos continentes - em quepesem as disparidades regionais de desenvolvimento explicadas não pelas desi gual dades de aptidão inatas, mas pelas possibilidades desiguais oferecidas pela natureza - atados pelo futuro comum que os une como membros da humanidade. I psis verbis:

É do futuro enão do passado que se tomam as categorias universais, com as quais a realidade contingente do presente é percebida ejulgada, é no futuro e não no passado que se encontra o elo que congrega e une a humanidade. (Giesen, 1999:146)

No caso al emão, os intelectuais iluministas modificam os termos da relação entre humanidade enatureza, acentuando o paradoxo entrea natureza humana idiossincrática eindividual ea artificialidade do mundo burguês, surgindo daí o traço romântico queiria marcar mais tarde a constituição da nação alemã. A nação representada pelo povo unido pela cultura e pela ancestralidade comum se tornaria o terreno idealizado no qual a natureza individual e o mundo exterior se reconciliariam. A relação da concepção romântica da nação com o futuro, no caso alemão, é exatamente oposta àquela que se verifica no iluminismo francês. Para os românticos alemães, a Idade M édia é recoberta de um brilho que se perdera, é no passado que el es vão buscar as tradições que se quer reviver no âmbito da busca por "individualidade e autenticidade" (ibidem:178).

Parece evidente que é o desejo de sobrepor a força do progresso ao passado opressivo e a construção de uma identidade voltada para o futuro, próprios ao iluminismo francês, e não a ênfase na ancestral idade comum dos românticos alemães que marcam a reconfiguração da nação brasileira a partir dos anos 30.

N ão se trata, por isso, da construção de uma ideologia racial como afirma G uimarães, mas de uma ideologia nacional não racial, no sentido preciso de que "evita" a raça (D avis, 1999), enquanto critério legítimo deadscrição social - a meta-raça a queserefere Freyre ou a professada "unidade da raça" do discurso varguista (C arneiro, 1990:35) viram uma metáfora da nacionalidade, não são, portanto, conceitos raciais, mas não-raciais, a despeito de se valerem da semântica da raça. Isto é, raça só faz sentido no corpo 
de uma ideologia que diferencia e segmenta os grupos humanos conforme adscrições naturais, um discurso que rompe com tais distinções éum discurso não racial, o quenão significa, obviamente, que se trate de uma ideologia anti-racista ou não racista, ou mesmo que ela seja neutra com relação à permanência das desigualdades raciais. Enfatize-se, contudo, que não se trata de uma ideologia racial, mas deuma ideologia nacional, com múltiplas dimensões.

Em sua dimensão política, a ideologia nacional que se constrói a partir de 1930 apresenta o caráter inclusivista/ assimilacionista do modelo francês, dispensando claramente o requisito da ancestralidade comum como condiç̧ão de pertença à nação. $0 \mathrm{~s}$ traçosquedistinguem os dois model os são a ênfasena participação cívica e na igual dade substantiva entre todos os cidadãos, ausentes do modelo brasileiro. C omo se sabe, à igualdade jurídica não corresponde, no Brasil, uma igualdade efetiva no que tange ao gozo dos direitos civis e políticos.

A ideologia da mestiçagem comporta, como em outros países latino-americanos (cf. M artinez-Echazábal, 1998), uma dimensão de gênero. Tanto no trabal ho de Freyre quanto no âmbito do esforço consistente de institucional ização de uma ideologia nacionalista no Estado Novo, reifica-se a imagem da mulher sem subjetividade própria esem vida cívica e política autônomas; nesse constructo, a mulher realiza-se e se completa enquanto objeto do desejo masculino. ${ }^{5}$

Em sua expressão social, a ideologia da mestiçagem é aristocrática, romantiza as desigualdades, banalizando-as. N ão há, contudo, uma justificativa moral para as desigualdades que esteja apoiadana crença em al guma hierarquianatural/biológica entreos diferentes membros da nação, como se se acreditasse que os miseráveis fossem feitos de um "barro diferente", conforme a imagem de Souza (2000). Para que se transforme numa questão moral, a igualdade social precisa ser politicamente construída e individualmente internal izada como um valor, o que simplesmente não se deu na história brasileira. A justiça social não é um bem natural, é um valor político que determinada sociedade pode construir - ou não.

Em sua facecultural, tal ideologia procura disciplinar a heterogeneidade existente, selecionando, através da ação discursiva e política sistemática, aquelas manifestações que conformam a identidade nacional, restringindo-se expressões divergentes, daí seu traço heterofóbico. N ão me parece haver aqui uma supressão pre- 
ferencial da ancestralidade africana ou indígena como sugerem os estudos raciais, o que há é uma integração hierarquizada dos diferentes legados e a obliteração das marcas étnicas que pudessem ser entendidas como desagregadoras da nação idealizada. Sob tal aspecto - esomente sob tal aspecto - não há uma penal ização maior dos indígenas e afro-descendentes que dos demais imigrantes não europeus (ver, a respeito, a cuidadosa análise de Lesser, 1999) ou da população-alvo da Campanha de $\mathrm{N}$ acionalização varguista (Seyferth, 1997).

Em sua dimensão racial, a ideologia da mestiçagem caracteriza-se por banir o conceito raça do debate público, o que apresenta obviamente resultadosambíguos. D e um lado, o racismo biologicista perde sua legitimidade imanente; de outro, o racismo presente nas relações enas estruturas sociais permanece intocado. No âmbito de tal ideologia e do conjunto de práticas políticas que a acompanha, a ênfase no branqueamento, no sentido biológico até então dominante, ésubstituída pelo discurso da modernização, no sentido econômico e social. Souza (2000, cap. 8) mostra que é a aquisi ção e adesão a isso que se idealizou serem as habilidades e os valores modernos que estrutura as hierarquias sociais no Brasil já desde o Século XIX. Essa dimensão da ideologia da mestiçagem, enquanto aposta no futuro e decorrente reificação da modernidade, parece-me, passadas tantas décadas, continuar relativamente intocada. É ainda a "religião civil" brasileira, elege presidentes, legitima políticas públicas excludentes e torna os "atrasados" culpados por sua miséria. É na conjunção com o nacionalismo modernizante que se reformulam ese general izam adscrições sociais negativas defundo racial eregional. Assim, no catálogo dos preconceitos estabelecidos, o negro em qualquer região carrega o estigma do atraso, o nordestino no Sul se transforma em sinônimo de subdesenvolvimento, ${ }^{6}$ e o país como um todo, diante de um mitificado "mundo desenvolvido", mais tarde "Primeiro M undo", se auto-representa como a encarnação do atraso.

0 mito que persistiu desde os anos 30 eque pareceir se desconstruindo a partir dosfinais dos anos 70 éo da brasilidadeinclusiva eaberta, capaz de integrar em seu interior harmonicamente as diferenças. D e fato, fenômenos como a rearticulação do M ovimento $\mathrm{N}$ egro, 0 surgimento de um movimento feminista, a tematização pública do homossexualismo, o crescimento das igrejas não católicas, o fortalecimento do movimento indígena, a reconstrução de uma etnia quilombola e a recuperação de uma etnicidade híbrida por parte de descendentes de imigrantes conformam 
um contexto de plural ismo cultural que contrasta com a imagem, que se estrutura desde $V$ argas, da nacionalidade unitária capaz de retraduzir todas as reivindicações de reconhecimento da diferença sob a chave da brasilidade. Trata-se, portanto, não da afirmaçã̃o do caráter multirracial do Brasil, como sugerem os estudos raciais, e da decomposição decorrente dos elementos raciais que teriam composto a nação - branco, negro, índio - , mas de uma desconstrução étnico-cultural e da afirmação do caráter multicultural em oposição à ideologia da mestiçagem que fundira - e ao fazê-lo apagara - as diferenças. Com efeito, o índio não se reidentifica como raça, mas como M unduruku ou Xavante, o branco se reidentifica como descendentedeital ianos ou al emãese, mesmo a reidentificação dos afro-descendentes, apesar da referência discursiva à raça como substituto das pertenças étnicas obliteradas pela escravidão, não se dá, como se mostrará mais adiante, necessariamente no termos da construção de uma identidade racial. A mulher, por sua vez, busca também conquistar uma posição na gramática nacional distinta daquela que Ihe conferiu a ideologia da mestiçagem, afirmando sua autonomia emocional esua condição de sujeito. É esse mito da democracia cultural, isto é, a crença compartilhada coletivamente de que o Brasil aceita e al imenta a diversidade, que vem perdendo sua eficácia simbólica nos últimos anos.

0 mito de queo país não éracista aparece enquanto elemento constitutivo de uma construção política mais abrangente e começa a ser desfeito, pelo menos no plano cognitivo, desdeo estudo piloto da U N ESCO , pionei ro em indicar o racismo ocultado sob o discurso da democracia racial. 0 bviamente não se está afirmando que o Brasil se tornou menos racista depois que, nos anos 1950, começaram a vir à luz as desigualdades raciais. Assim como o familismo, o clientelismo ou o personalismo, as adscrições raciais atuam como prática social que molda as oportunidades individuais, além e acima dos méritos pessoais. Como essas outras práticas, 0 racismo é, háal gum tempo, reconhecido socialmentee condenado publicamente pela maioria das pessoas, como indicam recorrentemente os surveys de opinião. ${ }^{7} 0$ u seja, a ausência de racismo, assim como a ausência de familismo ou de clientelismo, permanecem como valor eideal, malgrado sua fraca materialização nas práticas sociais. A justiça social, em contrapartida, não parece ter o estatuto deuma questão moral para a sociedade, na medida em queas desigualdades sociais são explicadas pelo rasgo modernizante da ideologia da mestiçagem, mantido infenso às desconstruções da identidade nacional. 
Esse desfecho não tem o sentido de reduzir a importância do combate ao racismo ou de dizer que sua superação éum problema de segunda ordem. Já está sobejamente demonstrado que as desigualdades raciais não desaparecem com a modernização, ao contrário, seagravam com ela, clamam, por isso, por medidas específicas de tratamento como a reeducação cívica, as políticas de ação afirmativa etc. É nesse âmbito que os estudos raciais revelam sua importância teórica e política; é também nesse espaço que se sustenta a plena legitimação e justificação das ações de instituições e fundações- sua procedência, sebrasileira ou estrangeira, não apresenta aqui qual quer relevância - que apóiam o combate ao racismo.

Raça e I dentidade Afro-D escendente

A raça não tem, no âmbito do campo dos estudos raciais no B rasil, um estatuto biológico, ou seja "as raças não são um fato do mundo físico, elas existem, contudo, de modo pleno, no mundo social" (G uimarães, 1999:9ss.), produtos de formas de classificação sociais com implicações substantivas para as oportunidadesindividuais no interior dos diferentes grupos sociais. Por decorrência, o racismo é entendido como "uma forma bastante específica de 'naturalizar' a vida social, isto é, de explicar diferenças pessoais, sociais e culturais a partir de diferenças tomadas como naturais".

0 uso sociológico da categoria raça como polarização branco/não branco seria legitimada pela constatação dos chamados estudos "estruturalistas" (cf. W inant, 1994), no final dosanos 70, de que as desigual dades sociais entre os diferentes grupos étnico/cromáticos distinguidos nas estatísticas oficiais do Instituto B rasileiro de G eografia eEstatística(IBGE) - preto, branco, amarelo, pardo eindígena- poderiam ser reunidosem dois grandes grupos, ora chamados de brancos e não-brancos, ora chamados de brancos e negros. I sto refutaria as constatações dos estudos qual itativos que indicam uma gradação cromática nas adscrições sociais, de forma crescente do escuro para o claro - ou seja, quanto mais claro mais valorizado social mente - eque dão sustentação à tese de que o que existeno Brasil épreconceito ou discriminação de cor enão discriminação racial. Ao mesmo tempo, ficaria demonstrado que a discriminação dos não-brancos não se subsumena classe: mesmo isolando-se os fatores de classe, persistem desigualdades que só pode- 
riam então ser explicadas quando se introduz 0 par branco/não branco como ordem classificatória.

A essa "real idade estrutural" das desigualdades raciais se seguem conseqüências políticas. Isto é, se a classificação racial branco/não branco édeterminantedas oportunidades sociais, então ela devetambém conformar as identidades políticas, rompendo a cortina ideológica do mito da democracia racial que permite, no plano político, que a ordem racial desigual seja reproduzida. Por isso, para "os afro-brasileiros, para aquel es que chamam a si mesmos de 'negros', 0 anti-racismo tem quesignificar [...], antes detudo, aadmissão de sua 'raça', isto é, a percepção racializada de si mesmo e dosoutros" (G uimarães, 1995:43). Essa construção identitáriadeterminada pelo imperativo político de combater as estruturas que reproduzem as desigual dades raciais seria animada, tanto a partir da "cultura afro-brasilei ra" quanto pelo "legado cultural e político do 'Atlântico N egro' - isto é, o M ovimento pelos D ireitos Civis nos Estados U nidos, a renascença cultural caribenha, a luta contra o apartheid na África do Sul etc." (ibidem). E sse modelo racializado de identidade deveria ser tanto encorajado pelo Estado (Guimarães, 1999:190), quanto pela ação do M ovimento N egro. $\mathrm{H}$ anchard (1994:162), não obstante, orientado pela noção gramsciana de bloco histórico, pondera que a identidade negra a ser construída no Brasil deveser menos "diasporic" emais nacional, apostando na formação de um leque amplo de alianças.

0 processo de construção da "identidade racial" afro-descendentefoi estudado também no plano psicológico-pessoal. Partindo de estudos prévios elaborados nos Estados U nidos, como aqueles apresentados por C ross J r. (1995), Ferreira (2000) mostra que, no Brasil, a construção da identidade afro-descendente desenvolve-se de maneira distinta daquela estudada no contexto norte-americano. N ão obstante, percebe verificarem-se, também no B rasil, as fases distinguidas para o caso estaduniden se e queele traduz como: i) submissão, caracterizada pela internalização dos valores "brancos"; ii) impacto, fase marcada pelas experiências que tornam inevitável o reconhecimento da discriminação; iii) militância eidentidade autocentrada, quando a cultura branca éabsolutamente negada; e iii) articulação, a fase da alteridade.

Retomando-se aqui aquela distinção estabelecida no início deste artigo, entre os diversos trabalhos emomentos agrupados no campo dos estudos raciais percebe-se problemas e méritos analíticos diversos nas várias contribuições e dimen sões de tal campo de pesquisa. Sea categoria raça constitui recurso metodológico indis- 
pensável para a identificação das desigual dades raciais, o mesmo não se pode dizer, todavia, do uso do conceito como categoria geral de análise da dinâmica da sociedade brasileira.

Com efeito, estudos como o trabalho de $\mathrm{H}$ asen balg $\&$ Silva (1988) e as atualizações recentes (ver, p. ex., Silva \& H asenbalg, 1999; Silva, 2000) corrigem a visão de senso comum dequeas “desigualdades raciais" foram herdadas do passado escravocrata e que tendem a desaparecer. Tais estudos evidenciam que as chances de ascensão social para "pretos" e "pardos" continuam muito menores que para os brancos, mesmo quando se isolam os determinantes ligadosà origem social. A o mesmo tempo, quando se restringeao estudo das desigualdades raciais, o agrupamento das categoriasutilizadas pelo IBGE "pardos" e "pretos" no pólo "não branco", em contraposição a "branco", conferevisibilidadeàs adscrições raciais que co-determinam as injustiças sociais no Brasil, constituindo, ao contrário do que afirma a crítica de Bourdieu eW acquant referida acima, contribuição analiticamente legítima e, do ponto de vista de uma política anti-racista, preciosa e indispensável.

O s problemasteóricos surgem quando se deduz do exercício metodológico de agrupar polarizadamente as diferenças estruturais a categoria raça como chave interpretativa para se estudar a sociedade brasileira.

Em primeiro lugar, há que se dar conta de que, conforme os dados coligidos por Schwartzman (1999), al gumas diferenças sociais entre "brancos" e "amarel os" em favor dos amarelos são semeIhantes àquelas existentes entre brancos, de um lado, e pretos e pardos, de outro. ${ }^{8}$ Ao mesmo tempo, o fato de o grupo indígena apresentar perfil de desfavorecimento social semelhante àquele dos pardos e negros não autoriza a tratá-los como não-brancos, logo negros, esquecendo-se do viés étnico evidenteda categoriaindígena. ${ }^{9}$ Por outro lado, o cruzamento entre o nível de renda e a "origem" (se árabe, japonesa, espanhola, africana etc.), possivelmente em função das redes sociais próprias a cada um desses grupos populacionais, pode também ter um peso importante na co-determinação das desigualdades sociais (cf. Schwartzman 1999:94).

Ressalte-se ainda com muito mais ênfase, dada a sua abrangência e sustentação na bibliografia, a clivagem de gênero como igualmente determinante das chances sociais, para além dos méritos pessoais. Como mostra Lovell (1995), as mulheres sofrem discriminação ocupacional - medida através da chance de obtenção dos postos mais cobiçados - , e sal arial - avaliada pela comparação 
entre os rendimentos de pessoas com igual nível de qualificação - , que têm mecanismos distintos, mas cujo grau de injustiça é comparável àquele que afeta a população afro-descendente. ${ }^{10}$

A existência da clivagem de gênero, das clivagens de classe e de outras possíveis clivagens como a de "origem" - a ser ainda adequadamente estudada - mostram que, do ponto de vista de sua reprodução estrutural, outros fatores concorrem com a raça como determinantes estruturais das desigual dades sociais no B rasil. N esse sentido, a reunião dos diferentes grupos populacionais nos pólos branco/não-branco - recurso indispensável para desnudar a dimensão racial das desigualdades sociaisno B rasil - revela-seinsuficiente como matriz analítica explicativa das múltiplas estruturas hierárquicas existentes no País.

A objeção, por assim dizer, construtivista à generalização do uso sociológico da categoria raça associa-se ao modo como, no âmbito dos estudos raciais, as relações entre estruturas sociais e relações sociais são interpretadas. Chama-se a atenção, aqui, para o fato de que, sem 0 apoio em estudos qualitativos que permitam identificar a forma como a dinâmica racial efetivamente opera no plano das relações sociais, não se pode pressupor, a partir da possibilidade de agrupamento das desigualdades nos pól os branco-não branco, que a sociedade efetivamentefunciona com basenessa polaridade. 0 u seja, níveis e mecanismos de desigualdade semelhantes não correspondem a processos de desfavorecimento edediscriminação, no plano das relações sociais, necessariamente símiles. ${ }^{11}$ Se se ignora tais distinções, raça acaba funcionando como um mal sucedâneo da categoria classe na sociologia marxista, na medida em queabrangee subsumetodas as outras adscrições sociais (sobre tal problema, ver W ade, 1997:112).

0 problema teórico que se detecta aqui éo de tomar a realidadesocial como um reflexo unilateral da estrutura socioeconômica, não levando em conta a forma como os agentes sociais decodificam as estruturas e constroem os significados que orientam seus comportamentos e escolhas.

A conseqüência imediata de tal operação sociológica é de que se trata indiferenciadamente como racismo múltiplas adscrições negativas - denatureza cultural, de gênero, étnica- que, mesmo que possam ter conseqüências distributivas semelhantes, não são indiferenciadas, quando observadas do ponto de vista das pessoas concretas nelas envolvidas. N esse caso, como conceito geral, parece-mequea categoria segregação traduz mel hor a realidadesocial das relações desiguais, na medida em quecomportasimultane- 
amente a relação moral de reprodução das hierarquias e as formas diversas em que a assimetria social se expressa material mente - 0 acesso desigual a bens sociais como escola, equipamentos urbanos, rendimentos etc. Permite também a construção de atributos que qualifiquem a situação particular de humilhação moral e de desigualdade social, podendo-se referir a uma segregação de gênero, social, cultural, étnica, espacial euma propriamenteracial, queseria adequadamente chamada de racismo.

N ote-seque, mesmo no caso particular do racismo, ou seja, a adscrição negativa baseada naqueles traçosfenotípicos que o sen so comum classifica como raça, parecenão se observar uma dinâmica de segregação fundada na polarização branco/negro. I sto é, quando se considera ambas as dimensões da segregação racial - a estrutural e a moral - observa-se que, ainda que possa haver, no plano material, uma dinâmica polarizada de reprodução das desigualdades, os estudos qualitativos revelam que, no plano moral, o racismo obedece a regras múltiplas e que variam conforme a esfera social considerada (cf. Sansone, 1996).

A concepção de identidade cultural e, como se viu, também pessoal, subjacente a al guns estudos raciais, reflete igualmente 0 objetivismo estruturalista, na medida em que estabelece, a partir do grau de conhecimento e da internalização da polarização branco/negro, uma escala evolutiva que permite falar de níveis distintos de "consciência racial" (H anchard, 1994, cap. 4). Ao hierarquizar os modelos identitários, os estudos raciais incorrem em problemas variados.

Em primeiro lugar, verifica-se queos estudos raciais hipostasiam a dimensão racional-cognitiva da identidade, fazendo dela a matriz a partir da qual as escolhas estéticas, simbólicas, culturais devem ser feitas. 0 ra, como se sabe, no maistardar desde a consolidação da perspectiva construtivista no âmbito dos estudos de gê nero, a "identidade deum grupo não sedefine por um conjunto de fatos objetivos, ela é o produto de significados experenciados" (Young, 1995:161). Corresponde, por isso, a processos pessoais e coletivos de busca econquista de reconhecimento social eenvolve, assi $m$, um conjunto complexo deescol has enegociações múltiplas e simultâneas, que são informadas por mitos, desejos, experiências e conhecimento. N ão há, nesse sentido, um ponto arquimediano fora da história efora das relações sociais que permita julgar as experiências sociais e coletivas, qualificando de falsa consciência aquelas construções identitárias não articuladas a partir do conhecimento legado por uma leitura sociológica particular das relações 
sociais no Brasil. Seguramente, édesejável queas desigual dades raciais sejam analisadas em todas as suas dimensões e que os resultados de tais estudos sejam amplamente divul gados, permitindo que tanto os que sofrem, quanto os que se beneficiam da opressão racial possam rever suas concepções. N ão cabe, contudo, aoscientistas sociais construir, artificialmente, um lugar epistemológico acima dos processos históricos concretos, julgando a partir dele quais são as escol has identitárias e as formas culturais de vida válidas.

Analiticamente, a superposição entre raça negra, cultura negra e identidade negra postulada por al guns estud os raciais étambém problemática. Isto é, a suposição de que a promoção de uma identidade coletiva apoiada na cultura afro-brasi leira e no legado do "Atlântico N egro" reconstruirá o elo entre o grupo populacional que carrega no corpo aqueles traços físicos responsáveis pelo desfavorecimento estrutural ea "consciência racial" encontra difícil sustentação empírica.

Como mostra Gilroy (2000, esp. cap. 7), o autor quemelhor sistematizou a tese do "black Atlantic", as expressões culturais da diáspora africana conformam um campo complexo, marcado por múltiplas determinações como o viés de gênero e a "axiologia do mercado" (ibidem:268). Ao mesmo tempo, o legado cultural do Atlântico N egro tornou-se uma metal inguagem de protesto polivalente contra situações opressivas diversas como mostra, por exemplo, a expansão do rap entre os descendentes de imigrantes marroquinos ou argelinos na periferia de Paris, ou a invenção do oriental hip hop pelosjovens turcosem Berlim que, seautodenominando negrosalemães, buscam cindir o ideal depurezaque orienta a construção da nacionalidade na Alemanha e impede sua plena integração cultural (cf. G reve, 2000). N ão existe, portanto, um vínculo linear e imediato entre o legado cultural do Atlântico $\mathrm{Ne}$ gro e um grupo populacional que, por apresentar determinadas marcas fenotípicas, deve tomar consciência de sua "raça".

Parece igual mente equivocado tratar os processos culturais de "reafricanização" verificados no Brasil contemporâneo como genericamente orientados pela perspectiva da "racialização das relações sociais". Trata-se, na verdade, de processos de construção de uma "etnicidade negra" (Sansone, 1999), nos quais a cultura não é uma variável dependente da política anti-racista e a estética não é um mero instrumento da "consciência racial". Tais manifestações têm uma lógica e uma dinâmica culturais próprias, não são, portanto, uma variável dependente da ação política. 
Ao hierarquizar as escolhas e os padrões identitários efetivamente existentes, al guns estudos raciais acabam traduzindo as diferenças substantivas entre a auto-identidade dos afro-descendentes brasileiros e a imagem ideal izada do afro-descedente"consciente de sua raça", como um lapso temporal que faz a construção identitária efetivamente existente no Brasil um pré-estágio "alienado" da "identidade oposicionista afro-brasileira" (French, 2000:118). Esse tipo de posição é recusada mesmo por estudiosos das desigualdades raciais, uma vez que, conforme $\mathrm{H}$ asenbalg (1992:159) "passa um trator em cima da identidadeque as pessoas têm". J. Batista Félix, conhecida liderança negra paulistana, manifesta insatisfação semelhante mostrando, ao estudar os bailes "black", que:

Q uando olhamos internamente o que temos é um grupo bem heterogê neo. Esta diversidade precisa ser entendida como uma forma legítima de existência. Assim não é legítimo simplesmente assumir que todos são simplesmente "negros" [...]. Propomos que os estudos sobre identidade levem em conta, definitivamente, este "arco-íris" como forma característica brasileira deproceder em nossa sociedade. Elanão ésó uma forma de não-dizer, denão-ser, muito pelo contrário. M uitas vezes, esta nossa particularidade afirma e revela muita coisa. (Félix, 2000:163)

Ressalte-se que nem mesmo o pragmatismo político pode justificar o objetivismo evolucionista constatado em muitos estudos raciais. Afinal, a relação causal entre a racialização das relações sociais e a reversão da situação de desfavorecimento dos afro-descendentes pode ser tratada no máximo como hipótese de trabalho ou desiderato político. ${ }^{12}$ Isto é, na medida em quenunca foi aplicada ao caso brasileiro, a tese de que o fortalecimento da consciência racial e a decorrente "racialização das relações sociais" constituem o caminho por excelência para combater o racismo apresenta 0 mesmo estatuto teórico da tese oposta, a qual sustenta que o racismo será vencido não através da promoção deuma política identitária, mas por meio da criação de condições político-institucionais para que o fenótipo não tenha qualquer influência sobre o exercício da cidadania, defendida por autores como Reis (1997). ${ }^{13}$

Por último, se se toma por base o estudo criterioso de H ofbauer (1999) sobre o branqueamento e, particularmente, sua análise comparativa entre a Frente N egra B rasileira - FN B dos anos 1930 eo M ovimento N egro U nificado - M N U contemporâneo, percebe-sequeas relações entre raça eidentidade cultural não seguem, no discurso das lideranças negras contemporâneas, o es- 
quema evolucionista e instrumental propugnado por Guimarães, $\mathrm{H}$ anchard ou French. Conforme o autor, "diferentemente da FN B que percebia claramente um hiato entre os val ores da 'civilização' (= 'cultura') ansiados e propagados pelo grupo e os valores vividos pela gran de mai oria dos 'negros atrasados', a nova militância pressupõe uma essência valorativa comum em todas as manifestações empíricas do negro", incluindo-se aqui o conjunto de expressões culturais do mundo do C adomblé e uma cosmovisão correspondente, no interior da qual não cabe, conforme mostra H ofbauer, a polarização branco/negro. Pode-se afirmar assim que, ao contrário da instrumentalização do repertório cultural afro-brasileiro e do Atlântico N egro para a construção da "consciência racial" e o restabelecimento do nexo (socio)lógico entre cultura negra, raça negra e identidade negra preconizado por alguns estudos raciais, os discursos das lideranças do M N U pesquisado por $\mathrm{H}$ ofbauer indicam que estas reconhecem a pluralidade das formas culturais de vida dos diversos segmentos da população afro-descendente, atribuindo a todas eles um valor intrínseco. ${ }^{14}$

\section{Conclusões}

A julgar pel as reações despertadas (French 2000), a crítica de Bourdieu \& W acquant (1998) aos estudos raciais, nos termos em que foi construída, prestou-se unicamenteà reafirmação da oposição artificial entre os supostos defensores da "democracia racial" brasileira, deum lado, e os autores sensíveis à "opressão racial" efetivamente existente, de outro - para se valer aqui dos termos através dos quais $\mathrm{H}$ anchard (1996) resumira, anos atrás, uma polêmica semel hante com o antropólogo Peter Fry, daU niversidadeFederal do Rio de Janeiro.

Esse tipo de redução discursiva quetransforma o debate acadêmico numa (falsa) disputa moral em torno do monopólio de proteção das vítimas de alguma forma social opressiva, seja ela 0 racismo brasileiro ou o imperialismo americano, pouco ajuda a reflexão teórica em torno das mazelas sociais existentes e dos meios políticos adequados para combatê-las.

Procurou-se, neste artigo, restringir-se ao exame de al guns dos desdobramentos anal íticos dos estudos raciais. Conforme se mostrou, o conceito não biológico de raça utilizado pelos estudos raciais desde finais dos anos 70 constitui contribuição fun damental para desnudar o viés racista que marca a produçãao e a reprodu- 
ção das iniqüidades sociais no Brasil. Q uando setrata da perpetuação das desigualdades estruturais, no lugar do recorrentementereclamado "continuum de cores", pode-se en xergar efetivamente, ao lado de outras clivagens, a polarização racial. É exatamente nesse âmbito quesesitua o campo deval idação teórica da idéia de raça.

Q uando transformada, contudo, em categoria analítica geral, utilizada para o estudo de outros fenômenos sociais, a idéia de raça perde sua eficácia teórica. Assim, quando é acionada para interpretar a formação nacional brasilei ra, a categoria conduz a uma interpretação reducionista do ideário nacional de dimensões múltiplas, construído a partir de 1930, levando a que alguns fenômenos recentes, melhor caracterizados como processos de desconstrução discursiva da nação, sejam tratados como afirmação do caráter multirracial do país. D e forma análoga, o uso da noção de raça como matriz explicativa última de todas as adscrições sociais negativas faz com que diferentes processos de segregação sejam inapropriadamentetraduzidos como um racismo fundado na oposição branco/não-branco.

Por último, a centralidade analítica conferida à raça nos estudos raciais leva a uma visão evolucionista da "autoconsciência" da população afro-descendente, transformando a identidade pessoal e cultural em dimensões subordinadas e instrumentais ao objetivo político de internalizar a polaridadeestrutural entrebrancos e não-brancos.

A ênfase na importância da pluralidade cultural defendida nesse artigo não denota nenhuma resignação política ou teórica, como se a crítica social não fosse possível e todas as formas de sociedade, incluídas aquelas segregadoras e racistas, por definição legítimas. A perspectiva crítica deveser construída, contudo, em conexão com as aspirações por reconhecimento efetivamente dadas, não pode se basear unilateralmente num projeto teórico-político anterior e externo aos processos sociais concretos.

$\mathrm{N}$ otas

1. Além do parecer anônimo daEAA, este artigo se beneficiou dos comentários de W ivian W eller, J essé Souza, M yrian Santos, 0 mar R ibeiro T homaz, U rsula Ferdinand, Renate R ott, Sérgio Luis Silva, LuisEdmundo M oraeseAndreasH ofbauer. Registro meu agradecimento aos colegas, sem fazêlos naturalmente co-responsáveis por eventuais incorreções constantes da presente versão.

2. M esmo que não possa ser adequadamente desenvolvida nos limites desse artigo, registre-se que a idéia de reconhecimento social aqui utilizada remete, fundamental- 


\section{Sérgio Costa}

mente, a C harles T aylor (1994) e Axel H onneth (1994a, 1994b) e diz respeito, no plano epistemológico, ao lugar de ancoramento social de uma perspectiva teórica crítica (tal argumento encontra-semel hor desenvolvido em Costa\& W erle, 2000).

3. Concebida detal maneira, "raça histórica" corresponde às definições de etnia que se tornaram clássicas, como aquelas reunidas por H utchinson \& Smith (1996). Como mostrar-se-á mais adiante, a indistinção entre etnia e raça leva a uma superposição entre cultura e traços fenotípicos, analítica e politicamente problemática.

4. A comparação deSenkman (1997:133ss) entreo varguismo eo peronismo éesclarecedora para mostrar como a lógica identitária em ambos os casosnão "buscava excluir, masintegrar todos osagregados ao povo para redefinir a nova nação". Assim, seincluem, no caso brasileiro, na nova identidade nacional, "as massas urbanas de cor", tratadas até a República Velha, pela oligarquias cafeeiras, como "um 0 utro no interior da nação" (p. 133).

5. Não se está afirmando obviamente que o patriarcado foi inventado no Barsil nos anos 1930. $\mathrm{N}$ o âmbito do $\mathrm{E}$ stado $\mathrm{N}$ ovo, contudo, a ênfase conferida à pátria eà família (ver C arneiro, 1990) reconstrói, sob uma chave conservadora, as funçõesfemininas tradicionais, neutralizando, ideol ogicamente, as transformações estruturais modernizantes que, desdeo século XIX, redesenhavam o lugar de inserção da mulher na estrutura social brasileira (ver Costa, E. V., 2000, cap. 10). Com efeito, conforme mostra Levine (1998:120 s), ainda que as mulheres ganhem o direito ao voto - de resto, pouco valioso sob a ditadura - e vejam crescer significativamente no período sua partici pação no mercado de trabal ho, sobretudo no setor têxtil, o Estado N ovo é marcado pela existência de políticas sistemáticas voltadas para a promoção do papel da mulher como mãe e dona-de-casa.

6. C arece de plausibilidade a subsunção das adscrições regionais no âmbito das adscrições raciais contra os afro-descendentes operada por Guimarães (1999:55), ao afirmar que baianos e nordestinos passaram a ser "uma codificação neutra para os 'pretos', 'mulatos' ou 'pardos' das classes subalternas, transformados, assim, nos alvos principais do 'novo racismo' brasileiro". Ainda que possam partilhar de uma adscrição negativa que pode, em determindas situações, al cançar intensidade equivalente, negros e nordestinos seguramente não são simbolicamente construídos como categorias símiles esubstituíveis no repertório racista brasileiro. Pelo menos desde o final do Século XIX, constrói-se a imagem do "N orte", depois do N ordeste, como região inepta para o progresso e refratária à modernização eé, sob tal chave e não na polarização branco/negro, que deve ser buscada a explicação para o racismo de que se tornou vítima o nordestino no Sul eSudeste do País (ver AlbuquerqueJ r., 1999:68ss.)

7. Lembre-se aqui os dados da abrangente pesquisa do $D$ atafolha (Turra \& Venturi, 1995), segundo os quais quase $90 \%$ dos entrevistad os admitem que "os brancos têm preconceito de cor em relação aos negros" no Brasil (p. 96). A relativização da importância do mito da democracia racial é constatada de formas diversas. $\mathrm{H}$ asenbalg (1995:367ss.) mostra que há uma "clara percep ção de que as pessoas recebem tratamento diferenciado conforme sua cor", indicando que a "ideologia racial" que se mantém éaquela quereifica a ausência de "confronto racial". D eforma similar, $\mathrm{H}$ anchard (1994:43) nota o declínio do mito da democracia racial, entendendo queo que permaneceintocado éo mito da "excepcionalidade racial" brasileira. Constata-se, no 
último caso, contudo, a insistência em subsumir uma ideologia nacional abrangente num ideário racial, enquanto o mais razoável parece ser precisamente o contrário, ou seja, entender-se o componenteracial - o banimento discursivo das classificaçõesraciais - como parte de uma ideologia nacional.

8. ConformeosdadosdaPN AD de1997, no nível de escolaridadeem queas diferenças de rendimento mais favorecem os "amarelos" - 4 a 7 anos de escolaridade -, estes apresentam uma renda média mensal em torno de $R \$ 800,00$ contra $R \$ 350,00$ dos brancos, $R \$ 250,00$ para pardos e também para pretos, e $R \$ 200,00$ para indígenas (cf. Schwartzman, 1999:95).

9. A rigor, nos estudos sobre desigual dade racial, os grupos demográficos "amarelo" e "indígena" não são incluídos nas comparações, o queé compreensível quando se trata da comparação e da simulação estatísticas. Q uando setrata, contudo, da utilização de raça como categoriaanalítica geral , como fazem os estudosraciais recentes, os problemas aqui levantados ganham relevância.

10. Roland (2000) eSoares (2000) mostram, a partir de perspectivas distintas, as implicações importantes para as lutas anti-racistas decorrentes do duplo desfavorecimento das mulheres negras.

11. W inant (1994:138ss) busca resolver o problema de não reduzir raça a uma categoria estrutural, introduzindo a perspectiva da "formação racial", segundo a qual raça compreendetanto o plano micro da "psiquêindividual e dos relacionamentos entre indivíduos relações individuais [quanto] o nível macro dasidentidades coletivase estruturas sociais" (i bidem:139). A sugestão do autor, contudo, parecenão solucionar a dificuldade analítica de compatibilizar a relevância da raça como ordenadora das oportunidades pessoais e a multiplicidade de fatores que estruturam os relacionamentos e identidades sociais.

12. A convicção de quea polarização racial das relações sociais combaterá o racismo revela, implicitamente, uma concepção do poder e da política semel hante àquela que Castoriadis (1995) identificou no marxismo. O u seja, a política é tratada, na imagem emprestada da Física, como um campo vetorial, cuja resultante expressa a "correlação de forças" existente, daí a necessidade defortalecimento do suposto pólo frágil do campo de forças, de sorte a fazer a história se mover numa direção determinada. Tal concepção desconsidera que, nas democracias contemporâneas, a política tornou-se, antes, o campo de disputas em torno da "construção de espaços sociais de reconhecimento" (M elucci, 1996:219). Aqui, os atores sociais não correspondem a vetores num campo de forças que se anulam reciprocamente; ao contrário, o poder destes é expresso pela legitimidade pública para "nomear" as experiências coletivas, vale dizer, definir os significados compartilhados social mente. V isto sob esta ótica, 0 eixo da luta anti-racista no B rasil passa a apoiar-se - como parece ser a estratégia de boa parte do movimento negro - na obliteração da legitimidade imanente de que se cobrem as práticas racistas e não mais na polarização das relações brancos/não-brancos propugnada por al guns estudos raciais.

13. $\mathrm{N}$ ão se trata aqui da adesão à tese de Reis de que se tome a democracia racial não como mito, mas como meta a ser al cançada. Conforme se mostrou em outro contexto (Costa \& W erle, 2000), a persistência cultural de hierarquias históricas, como 0 "branqueamento", justifica políticas voltadas para a promoção e val orização de for- 
Sérgio Costa

mas de vida historicamente subestimadas. A referênciaà importante contribuição de Reis visa aqui evidenciar o fato de que a tese da polarização racial éapenas uma entre outras formas preconizadas para o combate ao racismo.

14. A posição de militantes negros históricos como Abdias do $\mathrm{N}$ ascimento ( $\mathrm{N}$ ascimento $\& \mathrm{~N}$ ascimento, 2000) parece também dirigida nesses mesmos termos.

\section{Bibliografia}

ALBU Q U ERQ UE JR., D urval M . (1999). A Invenção do N ordeste e O utras A rtes. São Paulo/R ecife, C ortez/Fundação Joaquim $\mathrm{N}$ abuco.

ARAÚ JO, Ricardo B. de(1994), Guerra ePaz: Casa Grande\& Senzala ea O bra deG ilberto Freyrenos Anos 30. Rio de Janeiro, Editora 34.

BO URDIEU, Pierre\& W ACQ U AN T, Loïc (1998). “Sur lesR uses dela Raison Impérialiste". Actes de la Recherche en Sciences Sociales, nºs 121-122, pp. 109-118.

CARN EIRO, M aria Luiza (1990). "Sob a M áscara do N acionalismo. Autoritarismo e Anti-Semitismo naEraV argas (1930-1945)". EstudiosI nterdi sciplinariosdeA mérica Latina y el Caribe, vol. 1, nำ1, pp. 23-40

C AST O RIAD IS, Cornelius (1995). A Instituição I magi nária da Sociedade. São Paulo, Paz e Terra.

COSTA, Emília V. da (2000). The Brazilian Empire. M yths and $\mathrm{H}$ istories. Chapel $\mathrm{H}$ ill/L ondon, U niversity of $\mathrm{N}$ orth Carolina (ed. revista).

COST A, Sérgio \& WERLE, D enilson L. (2000). "R econhecer as D iferenças: Liberais, Comunitaristas e as Relações Raciais no Brasil". In L. A vritzer \& J. M . D omingues (orgs.), T eoria Social eM odernidade no Brasil. Belo H orizonte, Ed. da UFM G (versão prévia em N ovos Estudos C ebrap, n 49, 1997, pp. 159-180).

COST A, Sérgio (2001a). "A M estiçagem e seus C ontrários: Etnicidade e $\mathrm{N}$ acionalidade no Brasil Contemporâneo". Tempo Social, vol. 13, no 1.

COSTA, Sérgio (2001b). "Teoria Social, Cosmopolitismo e a Constelação Pós-N acional". N ovos Estudos Cebrap, no 59.

CRO SSJR., W illiam E. (1995). "In Search of Blackness and Afrocentricity: T hePsychology of Black Identity C hange". In H. H arris, H. Blue \& E. G riffith (eds.), Racial and Ethnic Identity: Psychological D evelopment and Creative Expression. London, Routledge, pp. 53-72.

D AVIS, D arrién J. (1999). A voiding the D ark - Race and the F orging of $N$ ational Culture in M odern Brazil. Aldershot, Ashgate Publishing.

FERREIRA, Ricardo F. (2000). Afrodescendente. I dentidadeem Construção. Rio de aneiro, Pallas/EDUC.

FREN CH , J ohn (2000). "The M issteps of Anti-imperialist Reason: Bourdieu, W acquant and $\mathrm{H}$ anchard's 0 rpheus and Power". Theory, Culture and Society, vol. 17, no 1, pp. 107-128.

FREYRE, Gilberto (1999). Casa Grande\& Senzala. (36ª ed.). São Paulo/Rio deJ aneiro, Record.

\section{8}


FELIX, J oão B. (2000), C hic Show e Zimbawe ea C onstrução da I dentidade nos Bailes "Black" Paulistanos. D issertação de M estrado em Antropologia, São Paulo, U SP, $192 \mathrm{pp}$.

GIESEN, Bernhard (1999). Kollektive I dentitäten. D ie Intellektuellen und die $\mathrm{N}$ ation 2. Frankfurt/M.

GILROY, Paul (2000). Against Race. Imagining Political Culture B eyond the Color Line. Cambridge, $M$ ass., $\mathrm{H}$ arvard U niversity Press.

GREVE, M artin (2000), “K reuzberg und U nkapani. Skizzen zur M usik türkischer Jugedlicher in D eutschland“. In I. Attia eH . M arburger, Alltag und Lebenswelten von M igrantenjugendlichen. Frankfurt/M ., IK O , S. 189-212.

GUIM ARÃES, Antônio S. (2001). "N acionalidadee N ovas I dentidades Raciaisno Brasil: U ma H ipótese de Trabal ho". In J. Souza (org.), D emocracia H oje. Brasília, Ed. UnB.

_ (2000). "Prefácio". In A. S. Guimarães \& L. H untley (orgs. ), T irando a M áscara. Ensai os sobre o Raci smo no B rasil. São Paulo, Paz eT erra, pp. 11-30.

_ (1999). Racismo e Anti-Racismo no Brasil. Rio de Janeiro, Ed. 34.

_ (1995). "Racismo e Anti-Racismo no Brasil". N ovos Estudos, no 43.

H AN CH ARD, M ichael (1996). "Americanos, Brasileiros e a Cor da Espécie H umana. U ma Resposta a Peter Fry". Revista da U SP, no 31, pp. 164-175

_ (1994). O rpheus and the Pow er. Princeton, Princeton U niversity Press.

H ASEN BALG, CarlosA. (1995). "Entreos M itose os Fatos: Racismo eR elações Raciais no Brasil". D ados, vol. 38, n², pp. 355-374.

__ (1992). "N egros e M estiços: Vida, C otidiano e M ovimento" (entrevista). In N . do V. Silva \& C . A. H asenbalg, RelaçõesRaciaisno Brasil Contemporâneo. Rio de Janeiro, Rio Fundo, pp. 149-164.

(1979). D iscriminação e D esigualdades Raciais no Brasil. Rio de Janeiro, G raal.

$\ldots$ _ SILVA, N elson do V. (1988). Estrutura Social, M obilidade e Raça. Rio de Janeiro, I uperj/V értice.

H O FBAUER, Andreas (1999). U ma H istória de "Branqueamento" ou o "N egro" em Q uestão. Tese de doutorado em Antropologia, São Paulo, FFLCH/U SP, 375 pp.

H O N N ETH , Axel (1994). Kampf um Anerkennung. Frankfurt, Suhrkamp. (1994). "The Social D ynamics of D isrespect: O $n$ the L ocation of C ritical Theory Today". Constellations, vol. I, no 2 .

HUTCHINSO N, John \& SM ITH, Anthony (1994). Ethnicity. O xford, O xford U niversity Press.

KRIEGER, H einrich (1940). D ie Rassenfrage in Brasilien. Archiv für Rassen- und Gesellschaftsbiologie. Vol. 34, no. 1, pp. 9-56.

LESSER, J effrey (1999). N egociating $N$ ational I dentity. I mmigrants, M inorities and the Struggle for Ethnicity in Brazil. D urham and London, D uke U niversity Press.

LEVIN E, Robert M . (1998). Father of the Poor? Vargas and his Era. Cambridge, C ambridge U niversity Press.

LO VELL, Peggy A. (1995). "Raça e G ênero no Brasil”. Lua N ova, n 35, pp. 39-71.

M AIO , M arcos C . (2000). “O Projeto U N ESC O : Ciências Sociais e 'C redo Racial Brasileiro'”. Revista da U SP, $\mathrm{n} \cong 46$. 
Sérgio Costa

M ARTIN EZ-ECH AZÁBAL, Lourdes (1998). "'M estizaje' and the D iscourse of $N$ ational/C ultural Identity in Latin America, 1845-1959". Latin America Pesrpectives, vol. 25, no 3, pp. 21-42.

M ELUCCI, Alberto (1996). Challenging Codes - Collective Action in the Information Age. Cambridge, $C$ ambridge $U$ niversity Press.

M U N AN G A, K abengele(1999). Rediscutindo a M estiçagem no Brasi I. I dentidadeN acional versus I dentidade N egra. Petrópolis, Vozes.

N ASC IM EN T O, Abdias\& N ASCIM EN TO, ElisaL. (2000). "Reflexões sobre o M ovimento N egro no Brasil (1938-1997)". In A. S. G uimarães \& L. H untley (orgs.), T irando a M áscara. Ensaios sobre o Racismo no Brasil. São Paulo, Paz e Terra, pp. 203-234.

N IN A RO DRIGUES, Raimundo (1935). Os Africanos no Brasil. (2ª ed.). São Paulo, Cia. Editora $\mathrm{N}$ acional.

O LIVEIRA VIAN N A, Francisco J. (1923). Evolução do Povo Brasileiro. São Paulo, M onteiro.

PIETERSE, Jan N . (1998). Der M elange-Effekt. In U. Beck (org.), Perspektiven der Weltgesellschaft. Frankfurt/M . Suhrkamp.

REIS, Fábio W. (1997). "M ito e Valor da D emocracia Racial". In J. Souza (ed.), M ulticulturalismo e Racismo: U ma Comparação Brasil/EU A. Brasília, Paralelo 15.

RO LAN D, Edna (2000). "O M ovimento das M ulheres N egras Brasileiras: D esafios e Perspectivas". In A. S. Guimarães \& L. H untley (orgs.), T irando a M áscara. Ensaios sobre o Raci smo no Brasil. São Paulo, Paz e Terra, pp. 237-256.

SAN SO N E, Livio (1999). From A frica to Afro: U seand A buse of A frica in Brazil. Amster$\mathrm{dam} / \mathrm{D}$ akar, SEPHIS, $46 \mathrm{pp}$.

_ (1996). "AsR elações Raciais em C asa G rande\& Senzala Revisitadas à Luz do Processo de Internacionalização e G lobalização". In M. C. M aio \& R. V. Santos (orgs.), Raça, Ciência e Sociedade. Rio de Janeiro, Fiocruz/CC BB, pp. 207-218.

SC H W ARCZ, L. (1993). 0 Espetáculo das Raças. São Paulo, Cia. das Letras.

SCH W ARTZM AN , S. (1999). "Fora de Foco: Diversidade e Identidades Étnicas no Brasil". N ovos Estudos Cebrap, no 55, pp. 83-96.

SEN KM AN , Leonardo (1997). "La Lógica PopulistadelaIdentidad y Alteridad en Vargas y Perón: Algunas I mplicaciones para los I mmigrantes". Cuadernos Americanos, no 66, pp. 130-152.

SEYFERTH , Giralda (1997). "A Assimilação dos Imigrantes como Q uestão N acional". $M$ ana, vol. 3, no 1, pp. 95-31.

SILVA, N elson do V. \& H ASEN BALG, Carlos A. (1999). "Race, Schooling and Social M obility in Brazil". Ciência \& Cultura, vol. 51, no 5/6, pp. 457-463.

_ (1992). Relações Raciais no Brasil Contemporâneo. Rio de Janeiro, Editora Record.

SO ARES, Vera (2000). "O Verso e o Reverso da Construção da Cidadania Feminina, Branca e N egra no Brasil". In A. S. G uimarães \& L. H untley (orgs.), T irando a M áscara. Ensaios sobre o Racismo no Brasil. São Paulo, Paz eTerra, pp. 257-282

SO U ZA, Jessé (2000). M odernização Se etiva: U m Reinterpretação do D ilema Brasileiro. Braślia, Ed. da UnB.

TAYLO R, Charles (1994). "T hePolitics of Recognition". In A. Gutman (ed.), M ulticulturalism. Princeton, Princeton U niversity Press, pp. 25-74.

60 
TURRA, Cleusa \& VENTURI, Gustavo (orgs.) (1995). Racismo Cordial. São Paulo, Editora Ática.

TW IN E, Francis (1998). Racism in a Racial D emocracy. TheM aintenance of W hiteSupre macy in Brazil. N ew Brunswick, Rutgers U niversity Press.

W ADE, Peter (1997). Race and Ethnicity in Latin America. London, Pluto.

WIEVIORKA, Michel (1999). "Contextualizing French Multiculturalism and Racism". Theory, Culture and Society, vol 17, no 1 .

W IN AN T, H oward (1994). Racial Conditions. M inneapolis, University of M innesota Press.

YO U N G , I. (1995). "Together in D ifference: Transforming the L ogic of G roup Political C onflict". In W. K ymlicka (ed.), T heRights of M inority C ultures. N ew York, O xford University Press, pp. 155-176. 